\title{
Physician reporting of venereal disease in Ceylon
}

\author{
W. L. FERNANDO \\ Superintendent, Anti-Venereal Diseases Campaign, Ceylon
}

\section{Purpose of the survey}

The present statistics for cases of venereal disease treated in Ceylon include those treated at Government Hospital clinics, but not those treated by private practitioners.

This survey was designed to ascertain the number of cases of early syphilis and gonorrhoea treated by general physicians in private practice in Ceylon in 1969. McKenzie-Pollock (1970) reported that in the U.S.A. four out of every five cases of V.D. were treated by private practitioners.

The following V.D. legislation exists in Ceylon: (1) V.D. Ordinance No. 27 of 1938 provides that V.D. should be treated only by Registered Medical Practitioners or specially authorized Indigenous Practitioners.

(2) V.D. regulations of 1943, formed under Section 2 and 3 of the Quarantine and Prevention of Diseases Ordinance, require that sufferers from venereal diseases should get themselves treated, and that medical practitioners treating such patients should notify the proper authority.

These regulations were intended to assist in the control of V.D., but although they are still in force, they do not serve much purpose as the most important factor in case detection and treatment is the wholehearted co-operation of infected persons and general practitioners. Furthermore, it has since been decided (Health Department Circular-Medical 33 of 30.4.57) to persuade people to attend voluntarily without recourse to law as far as possible.

General (private) practitioners report few cases but there is excellent reporting from the thirteen government V.D. clinics functioning under the Anti-V.D. Campaign of the Department of Health of the island.

Private practitioners may find it difficult to report

Received for publication March 14, 1972

Address: 16 Vaverset Place, Colombo 6, Ceylon cases and contacts because their patients may wish the information to be regarded as confidential.

\section{Survey methods}

There are about 1,000 general practitioners in private practice in Ceylon, excluding the indigenous or Ayurvedic practitioners who were excluded from the survey. Of this number only 218 are members of the Independent Medical Practitioners' Association.

A questionnaire was sent only to these 218 doctors. If they failed to respond to the first letter a reminder was sent after 2 weeks, and altogether 140 (64 per cent.) responded. The following information was requested:

No. of cases of infectious syphilis treated in 1969:...... No. of cases of gonorrhoea treated in 1969:......

No. of cases of other venereal diseases treated in 1969:......

Other figures available pertaining to venereal diseases:......

\section{Findings}

No. of physicians responding: 140 (64 per cent. of those approached).

No. of physicians not treating cases of early syphilis: 96 (69 per cent.).

No. of physicians not treating cases of gonorrhoea: 40 (29 per cent.).

44 physicians (31 per cent. of these responding) treated 227 cases of early syphilis.

100 physicians (71 per cent. of these responding) treated 1,751 cases of gonorrhoea.

31 physicians treated 306 cases of other venereal diseases.

It is to be noted that a large number of general practitioners denied having treated any cases of early syphilis. Nevertheless, the figures may be exaggerated for the following reasons: 
(1) Few general practitioners have facilities for dark-ground examination and some cases of early syphilis may have been diagnosed on clinical grounds only.

(2) Very few general practitioners have facilities for the diagnosis of gonorrhoea, including diagnosis by culture, and the clinical diagnosis may not have been confirmed.

It was found that 21 general practitioners reported that they referred all their cases of venereal disease to Government clinics. These comprised 21 cases of early syphilis, 78 cases of gonorrhoea, and 19 cases of other venereal diseases.

\section{Projection and conclusions}

Assuming that those general practitioners in private practice who did not respond and those who are not members of the Independent Medical Practitioners' Association treated cases at the same rate as those who did respond, we obtain the following figures:

\section{EARLY SYPHILIS}

140 general practitioners treated $(227-21)=206$ cases; therefore 1,000 general practitioners treated 1,471 cases of early syphilis.

\section{GONORRHOEA}

140 general practitioners treated $(1,751-78)=1,673$ cases;

therefore 1,000 general practitioners treated 11,950 cases of gonorrhoea.

\section{OTHER VENEREAL DISEASES}

140 general practitioners treated $(306-19)=287$ cases; therefore 1,000 general practitioners treated 2,050 cases of other venereal diseases.

At the Government V.D. clinics in 1969 the following cases were treated:

1,068 early syphilis.

4,048 gonorrhoea.

It is therefore concluded that:

(1) The number of cases of early syphilis treated by general practioners is relatively small as compared to that of gonorrhoea.

(2) General practitioners treat as many cases of early syphilis as are treated in the Government V.D. clinics.

(3) General practitioners treat about three times as many cases of gonorrhoea as are treated in the Government clinics.

(4) The numbers of cases of early syphilis and gonorrhoea treated by general practitioners are almost three times greater than those treated in Government clinics.

(5) Scarcely any of the cases treated by general practitioners enter into our statistics, which cannot therefore be said to give a true picture of the V.D. problem in Ceylon.

\section{Summary}

It is estimated that general physicians in private practice in Ceylon treat about three times as many cases of venereal disease (early syphilis and gonorrhoea) as are treated in the Government V.D. clinics.

Unless the cases treated by general practitioners are taken into account an accurate estimate of the incidence of V.D. cannot be arrived at.

\section{Reference}

McKenzie-Pollock, J. S. (1970) Brit. F. vener. Dis., 46, 114

\section{Déclaration des maladies vénériennes faites par les médecins à Ceylan}

\section{SOMMAIRE}

On estime qu'à Ceylan les médecins de médecine générale traitent, en clientèle privée, à peu près trois fois plus de cas de maladies vénériennes (syphilis récente et gonococcie) qu'il n'en est traité dans les cliniques vénéréologiques gouvernementales. Si l'on ne tient pas compte des cas traités par les médecins de médecine générale, on ne pourra pas arriver à estimer convenablement l'incidence des maladies vénériennes. 